\title{
Corn stover conversion to biofuels: DOE's preparation for readiness in 2012
}

\author{
Michael E. Himmel
}

Received: 28 May 2009/Accepted: 4 June 2009/Published online: 20 June 2009

(C) Springer Science+Business Media B.V. 2009

Today, the United States' Energy Independence and Security Act (EISA) of 2007 focuses on biofuels support research and development $(\mathrm{R} \& \mathrm{D})$ needed to enable achieving respective volumetric and cost targets. Indeed, the worldwide objective is to bring us closer to independence from transportation fuels derived from fossil resources. This Special Issue highlights key areas of science and technology that impact the rollout of viable corn stover biofuels processes by 2012 .

\section{History of the US DOE biofuels program}

I believe it is worthwhile, given the context of this Special Issue-and where all the contributors were supported at one time or another by the US Department of Energy (DOE) Office of the Biomass Program (OBP) - to examine the nearly forgotten history leading to this current state of technology. My first recollection after arriving at the Solar Energy Research Institute (SERI) in 1980 was the Biotechnology Research Branch's preparation for the international symposium, "Biotechnology for the Production of Chemicals and Fuels from Biomass," cosponsored by SERI and DOE and held in October

M. E. Himmel ( $\bowtie)$

National Renewable Energy Laboratory, Golden, CO 80401, USA

e-mail: Mike_Himmel@nrel.gov of that year in Vail, CO. The programmatic sponsorship at DOE was not organized into detailed offices as it is today. But this symposium, organized by R. Villet, the manager of the SERI Biotechnology Branch, may have been the first of its kind. Speakers included many well-known names and themes, including A. Fiechter (yeast regulation), R. Lewin (microbial genetics), J.P. van der Meer (production of microalgae), C. Wandrey (membrane reactors), C.D. Scott (fixed film columnar bioreactors), and R. Gomez (C. thermocellum as an ethanol producer). The following year, SERI and the Government of Quebec cosponsored the "Seminar on Hydrolysis of Lignocellulosics." This meeting was convened in Quebec in October of 1981 and represented the first time that SERI scientists contributed on the national stage regarding original science in biomass conversion. The meeting provided presentations by many scientists recognized today, including $M$. Ladisch (biomass pretreatment), R.P. Chambers (hemicelluloses hydrolysis), M. Paice (ethanol from spent sulfite liquor), B.S. Montenecourt (hypercellulolytic mutants of $T$. reesei), C. Cooney (thermophilic ananerobic bacteria), G. Emert (cellulose conversion processes), T. Jeffries (ethanol from xylose), and K. Grohmann (2,3 butanediol from bacterial fermentation).

In February of 1981, the first Annual Report (1980) from SERI (SERI/PR-621-754) to DOE was submitted as a 46-page document. The report's Preface, written by Karl Grohmann, states: 
"At present, the chemical industry is based on nonrenewable resources. As the availability of such resources declines and prices rise, market forces will motivate a quest for substitutes. To take advantage of this trend in market substitution (flexibility) toward fermentable chemicals, it is imperative to seek ways of resuscitating the microbial industry and, by the addition of sophisticated technology, make it competitive with the petrochemical industry." This report was the first to list a specific DOE WPA funding number (\#349-82) for the SERI-led project. Note that in 1980 most of the current tools for molecular cloning, determining protein structure, and modeling process pathways were still very much in their infancy. Prior to 1978-1979, the only sources of funding for biofuels research in the United States were the National Science Foundation, US Department of Agriculture Regional laboratories, and the Department of the Army.

R. Villet submitted the next report (FY 1981) to DOE Office of Alcohol Fuels (SERI/PR-232-1511) in May 1982. The Preface for this 150-page report begins, "This is a report of research and development performed during 1981 by SERI's Biotechnology Research Branch which feels that process economic evaluation is a key to optimizing $R \& D$ pathways and lower the cost of the research burden." Indeed, the work done at NREL for the DOE OBP follows the same strategy today.

In January of 1984, the FY 1982 and 1983 reports (SERI/PR-232-2205) were submitted to DOE in a two-volume series totaling about 250 pages. In early spring of 1982, the "Alcohol Fuels Contractors Review Meeting" was held in Burlingame, CA, which was the first time the DOE program organized a review of non-government contractors working on alcohol fuels. Although SERI researchers were not involved in the science agenda, breakout sessions were introduced as follows: L. Douglas (Pretreatment), Van Morriss (Enzymatic Hydrolysis research), B. Hoagland (Acid Hydrolysis Research) [this referred to concentrated acid methods], and L. Douglas (Separations Research). One very noteworthy take-home message for me from this early meeting was the consequences of allowing many of the DOE contractors to operate with minimum oversight from DOE (at this time, SERI was not administrating subcontracts under our Prime Contract). It was realized-and essentially made public at this meeting - that for at least 4 years, many of the contractors had been working with woody biomass obtained from northeastern furniture factories. This "sander dust" from hardwoods processing (sized at about 300 mesh) displayed very fast rates and high extents of conversion in pretreatment and enzyme hydrolysis - and thus, was absolutely inappropriate for biomass conversion research. This review meeting allowed the first public forum for discussing technology challenges within the program. And although considerable research time and resources had been expended, the group came to a consensus about the proper redirection of future work using more realistically sized materials.

The 1984 report (SERI/PR-232-2642) was much more extensive (about 400 pages) and was submitted with reference to funding under DOE Federal Technology Partnership (FTP) \#3491. This report included some real technology-changing studies, such as the development of new yeast strains, horsepower measurements from biomass milling operations, biomass pretreatment kinetics, and early attempts at discovering improved cellulase and hemicellulase enzymes. It is also interesting to note that beyond my own personal collection, I know of no other records or copies of the reports from these early years of funding from the DOE Biomass Conversion program.

In 1985, the program conducted the first peer review involving all SERI personnel as well as DOE contractors, the "Biochemical Conversion Program Semi-Annual Review Meeting." The review agenda and project descriptions were submitted to DOE in a 400-page report (SERI/CP-231-2726), with the actual FY 1985 report (SERI/SP-231-2878) following in May 1985 as a 90-page document. Consequences of this first program-wide review included reaffirming SERI's leadership role in the program, continuing most of the research projects, and terminating some less-promising technologies.

From 1986 until about 1990, the DOE program office was called "Biochemical Conversion," and R. Moorer led the DOE Program office from about 1986 to 1994 . Although leadership at DOE changed steadily over the next 20 years, the Biochemical Conversion Program continued to execute annual or biannual review meetings, followed by reports from SERI. Somewhere between 1988 and 1989, the program became known as the DOE/SERI Alcohol Fuels Program. In 1990, the program is listed as the 
DOE/SERI Ethanol from Biomass Program, and in a report prepared in April 1993; it is listed as the DOE/ NREL Biofuels Program or Biofuels Program/Ethanol Project. Of note is that in 1993, NREL submitted the first Annual Operating Plan to DOE, prepared as it is done today. Because annual progress reports since the mid-1990s are more readily available, I will not attempt to describe the more-recent highlights.

Over the past 30 years-and under a number of program names and managers-the DOE Biofuels program has sponsored much of the essential $R \& D$ needed to bring the current state of technology to the brink of large-scale demonstration and commercialization. This history of sustained and meaningful research support has clearly been critical to the high level of understanding that we boast today.

\section{This special issue}

This special issue was designed to highlight critical research topics in biomass conversion, many of which were outlined decades ago and documented in the early reports from the 1980s. Aden and Foust, as well as Foust and coworkers, present the lead articles in this special issue. These authors define the technoeconomic context of the corn stover conversion process and describe the specific tools used to estimate both the projected cost of ethanol in 2012 using NREL's State of Technology (SOT) and several other base case models. Foust and coworkers also address critical sustainability and environmental issues regarding a future biofuels economy based on corn stover. These authors stress the need for expert life cycle analysis of proposed bioenergy pathways and emphasize the importance of continuous communication between those working to improve biomass conversion processes technically and those working to understand associated environmental impacts.

Wolfrum and Sluiter initiate the methods papers by describing multi-variant data analysis models generated from near-infrared spectra and used for estimating the chemical composition of corn stover. Wolfrum and coworkers then describe new work comparing the historical detergent and dietary fiber analyses with more modern methods of determining cellulose, hemicellulose, and lignin content in both native and pretreated corn stover. Liu and coworkers describe the application of new nanoscale probes that comprise the fusion of green fluorescent protein with cellulose binding modules (CBM) for estimating the available reactive surface (faces) of cellulose. These probes have also been used to describe the CBM function on the cellulose surface using a single molecule imaging approach.

Next, Hess and coworkers review the outlook for the sustainability and availability of feedstocks important for the biomass conversion industry in North America. Templeton and coworkers present original research results on the variation in samplings of corn stover harvested in North America. They show that the variation in polysaccharide and lignin content is far greater than previously thought likely. The paper by Park and coworkers describes refinements for combining X-ray diffraction and NMR methods for estimating the crystalline cellulose contents in standard cellulose preparations. This information is critical for properly assessing the performance of new cellulase preparations destined for application in biomass conversion processes.

Regarding biomass pretreatment, Elander and coworkers summarize the prominent thermal chemical pretreatments in use today. These pretreatment methods, examined in detail by the Consortium for Applied Fundamentals and Innovation (CAFI) group, include ammonia fiber expansion (AFEX), ammonia recycle percolation (ARP), dilute acid, hot water, lime, and sulfur dioxide steam explosion. CAFI, founded by C. Wyman, took lessons from the earlier experiences of Alcohol Fuels Program regarding data quality and methodological consistency, and assembled a team of experts in pretreatment science willing to conform to standard practices. CAFI members share sources of feedstocks (prepared by NREL), hydrolytic enzyme preparations, and experimental protocols (especially material balance protocols). The work published by CAFI members can, therefore, be used to compare various pretreatment technologies applied to poplar, corn stover, and switch grass in a process relevant manner. Next, Azadi and coworkers present new research findings on the "chemical fingerprint" analysis of the principal chemical compounds found in the hydrolysate liquors of dilute acid pretreated corn stover. Ishizawa and coworkers describe the implication of delignification on subsequent dilute acid pretreatment of corn stover biomass. Specifically, they consider the question of 


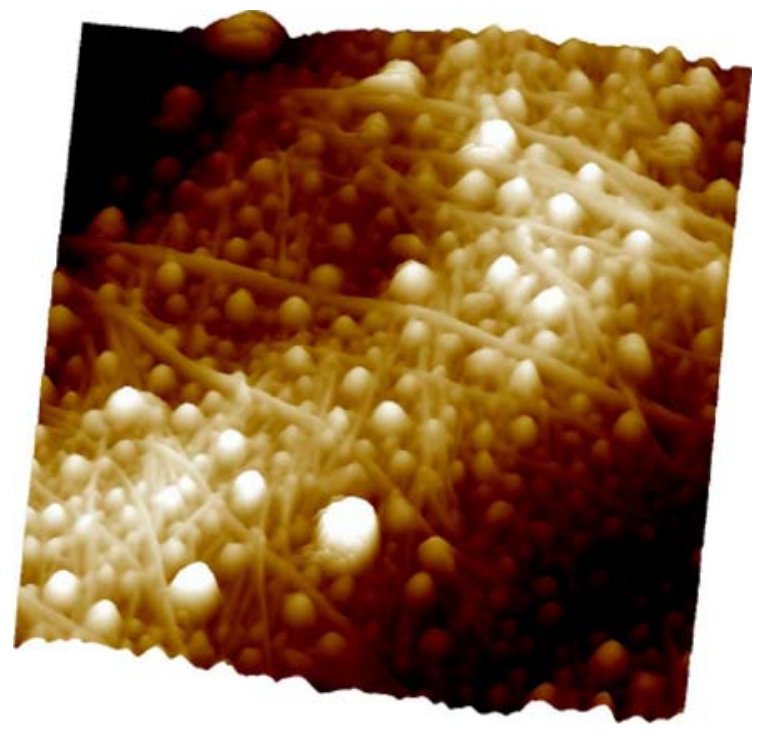

Fig. 1 An atomic force micrograph showing the topological structure of dilute acid-treated plant cell wall surface. Cellulose microfibrils are shown to remain intact and are seen as long fibrillar structures. Spherical particles presumably comprised of lignin and hemicelluloses can be seen in association with this thermochemically treated cell wall surface. The scan area is $1 \mu \mathrm{m} \times 1 \mu \mathrm{m}$. (Courtesy: Shi-You Ding, National Renewable Energy Lab)

whether it is possible that, under some conditions, removing lignin by certain means can result in a less digestible feedstock. I note here the considerable advantages new imaging modalities afford researchers working on the structure of biomass today. An example of this advantage is the atomic force micrograph of a section of dilute acid pretreated maize parenchyma cell wall surface shown in Fig. 1. This micrograph (provided by S.Y. Ding) clearly shows cell wall microfibrils studded by pools of coalesced lignins.

A review paper by Jovanovic and coworkers leads the topic of enzymatic saccharification of biomass. This paper describes the natural diversity - and thus, promise-for discovery of new glycoside hydrolases from fungi. The following paper by Adney and coworkers is an original research paper describing the recent discovery of the likely role-played by the natural glycosylation decorating the surface of the catalytic domain of cellobiohydrolase I from
T. reesei. Selig and coworkers next show that by first treating corn stover biomass with various pretreatments designed to retain or remove natural acetylation, and then testing the digestibility of these biomass preparations using purified enzymes, it is possible to pair critical enzyme cocktails with pretreatment chemistry. Wilson points out in the next paper that several microorganisms, which are capable of aggressive cellulose digestion, lack the critical exocellulase family 7 and 48 enzymes typically associated with an effective cellulase system. Of course, this opens new questions about the natural paradigms for cellulase action not yet discovered.

In the fermentation sciences, Knoshaug and coworkers describe the history of advances made toward the use and transport of L-arabinose by yeasts other than Saccharomyces, as well as their own recent progress in developing such strains. These authors also suggest critical research paths likely to lead to improved yeasts for corn stover biomass sugar fermentations. Finally, Pienkos and Zhang present a detailed assessment of the inhibitors likely to be formed by each of the dominant pretreatment chemistries being considered by industry today. Specific recommendation is also given for strategies that may relieve all or some of this inhibition, including membrane transport studies, directed pathway engineering, and random mutation selection of more robust cells.

From the perspective of one who has been involved in the 30-year history of the DOE Biofuels program, I am astounded by the level and detail of today's understanding regarding the conversion of corn stover and other feedstocks to bioethanol. Many of these topics are touched upon in this Special Issue of Cellulose. However, it is likely that with renewed interest and funding, new accomplishments in this field during the next few years will rival those from the preceding decades combined. This work would not have been possible without past and present support from the following DOE EERE staff: Jacques Beaudry-Losique, Valri Lightner, Valerie SariskyReed, Leslie Pezzullo, and Joyce Yang. 